\title{
Movement visualisation in virtual reality rehabilitation of the lower limb: a systematic review
}

\author{
Luara Ferreira dos Santos ${ }^{1,2^{*}}$, Oliver Christ $^{3}$, Kedar Mate ${ }^{4}$, Henning Schmidt ${ }^{5}$, Jörg Krüger ${ }^{1,5}$ \\ and Christian Dohle ${ }^{6,7}$
}

From Robotics: Science and Systems 2013 Berlin, Germany. 28-Jun-16

\author{
${ }^{*}$ Correspondence: \\ luara.santos@iwf.tu-berlin.de \\ ${ }^{1}$ Rehabilitation Robotics \\ Group (TU Berlin/ Fraunhofer \\ IPK), Department of Industrial \\ Automation Technology, \\ Technische Universität Berlin, \\ Pascalstr. 8-9, 10587 Berlin, \\ Germany \\ Full list of author information \\ is available at the end of the \\ article
}

\begin{abstract}
Background: Virtual reality (VR) based applications play an increasing role in motor rehabilitation. They provide an interactive and individualized environment in addition to increased motivation during motor tasks as well as facilitating motor learning through multimodal sensory information. Several previous studies have shown positive effect of VR-based treatments for lower extremity motor rehabilitation in neurological conditions, but the characteristics of these VR applications have not been systematically investigated. The visual information on the user's movement in the virtual environment, also called movement visualisation (MV), is a key element of VR-based rehabilitation interventions. The present review proposes categorization of Movement Visualisations of VR-based rehabilitation therapy for neurological conditions and also summarises current research in lower limb application.
\end{abstract}

Methods: A systematic search of literature on VR-based intervention for gait and balance rehabilitation in neurological conditions was performed in the databases namely; MEDLINE (Ovid), AMED, EMBASE, CINAHL, and Psyclnfo. Studies using non-virtual environments or applications to improve cognitive function, activities of daily living, or psychotherapy were excluded. The VR interventions of the included studies were analysed on their MV.

Results: In total 43 publications were selected based on the inclusion criteria. Seven distinct MV groups could be differentiated: indirect MV $(N=13)$, abstract MV $(N=11)$, augmented reality MV $(N=9)$, avatar MV $(N=5)$, tracking MV $(N=4)$, combined $\mathrm{MV}(\mathrm{N}=1)$, and no MV $(\mathrm{N}=2)$. In two included articles the visualisation conditions included different MV groups within the same study. Additionally, differences in motor performance could not be analysed because of the differences in the study design. Three studies investigated different visualisations within the same MV group and hence limited information can be extracted from one study.

Conclusions: The review demonstrates that individuals' movements during VR-based motor training can be displayed in different ways. Future studies are necessary to fundamentally explore the nature of this VR information and its effect on motor outcome. 


\section{Background}

Virtual reality (VR) in neurorehabilitation has emerged as a fairly recent approach that shows great promise to enhance the integration of virtual limbs in one`s body scheme [1] and motor learning in general [2]. Virtual Rehabilitation is a "group [of] all forms of clinical intervention (physical, occupational, cognitive, or psychological) that are based on, or augmented by, the use of Virtual Reality, augmented reality and computing technology. The term applies equally to interventions done locally, or at a distance (tele-rehabilitation)" [3]. The main objectives of intervention for facilitating motor learning within this definition are to (1) provide repetitive and customized high intensity training, (2) relay back information on patients' performance via multimodal feedback, and (3) improve motivation [2, 4]. VR therapies or interventions are based on real-time motion tracking and computer graphic technologies displaying the patients' behaviour during a task in a virtual environment.

The interaction of the user and Virtual environment can be described as a perception and action loop [5]. This motor performance is displayed in the virtual environment and subsequently, the system provides multimodal feedback related to movement execution. Through external (e.g. vision) and internal (proprioception) senses the on-line sensory feedback is integrated into the patient's mental representation. If necessary, the motor plan is corrected in order to achieve the given goal [5].

A previous Cochrane Review from Laver, George, Thomas, Deutsch, and Crotty [2] on Virtual Reality for stroke rehabilitation showed positive effects of VR intervention for motor rehabilitation in people post-stroke. However, grouped analysis from this review on recommendation for VR intervention provides inconclusive evidence. The author further comments that "[...] virtual reality interventions may vary greatly $[\ldots .$.$] , it is unclear$ what characteristics of the intervention are most important" ([2], p. 14).

Virtual rehabilitation system provides three different types of information to the patient: movement visualisation, performance feedback and context information [6]. During a motor task the patient's movements are captured and represented in the virtual environment (movement visualisation). According to the task success, information about the accomplished goal or a required movement alteration is transmitted through one or several sensory modalities (performance feedback). Finally, these two VR features are embedded in a virtual world (context information) that can vary from a very realistic to an abstract, unrealistic or reduced, technical environment.

Performance feedback often relies on theories of motor learning and is probably the most studied information type within VR-based motor rehabilitation. Moreover, context information is primarily not designed with a therapeutic purpose. Movement observation, however, plays an important role for central sensory stimulation therapies, such as mirror therapy or mental training. The observation or imagination of body movements facilitates motor recovery [7-9] and provides new possibilities for cortical reorganization and enhancement of functional mobility. Thus, it appears that movement visualisation may also play an important role in motor rehabilitation [10-12], although this aspect is yet to be systematically investigated [13].

The main goal of the present review is to identify various movement visualisation groups in VR-based motor interventions for lower extremities, by means of a systematic 
literature search. Secondarily, the included studies are further analysed for their effect on motor learning. This will help guide future research in rehabilitation using VR.

An interim analysis of the review published in 2013 showed six MV groups for upper and lower extremity training and additional two MV groups directed only towards lower extremity training. In this paper, we analysed only studies involving lower limb training, leading to a revision and expansion of the previously published MV groups findings [13-15].

\section{Methods}

An electronic search of published literature was performed based on the same keywords and search string as outlined by a previous Cochrane review [2] on virtual reality for stroke rehabilitation. Following databases were searched for relevant studies: MEDLINE (Ovid), AMED, and EMBASE databases were searched from inception to 21st November 2012, and the CINHAL, and PsycInfo databases were searched from inception to 4th December 2012.

Inclusion criteria were as follows: (1) experimental studies on motor rehabilitation for lower extremities, (2) VR visual feedback, (3) healthy participants or any neurological patient population, (4) at least one motor outcome reported. Exclusion criteria were (1) studies with non-virtual environments, and (2) applications focussing to train cognitive functions or psychotherapy. Also publications in languages other than English or German as well as publications or conference abstracts that did not contain sufficient information for the analyses were not included. Since the main goal of this review is to determine and compare various types of movement visualisations there was no exclusion based on the methodological quality of studies.

All search results were exported to bibliographic software (Citavi 4.1, Swiss Academic Software GmbH). One review author (LFS) screened paper titles retrieved from the search in order to exclude obviously irrelevant references. Abstracts or full texts or both of the remaining studies were obtained and used on the inclusion criteria to assess whether they were eligible for inclusion. Disagreements were resolved by discussion between two review authors (LFS and KM). The included articles were first analysed on their use of Movement Visualisation. This was done on the basis of the information provided in the article text and available images. Thereafter, study characteristics were then extracted in a tabular format which included: motor function, sample population, sample size, immersion, and use of robotic device. Immersion was categorized accordingly to Kalawsky [16] into non-immersive (desktop monitor), semi-immersive (large screen monitor or projection systems with more than $60^{\circ}$ wide angle display, with or without 3D shutter glasses), and fully immersive $\left(360^{\circ}\right.$ wide angle display, e.g. with a Head Mounted Display). Additionally, categories of augmented reality (real world supplemented with virtual information) and commercial gaming system (systems that have not been designed for rehabilitation purposes) were used.

\section{Results}

A total of 4240 articles were identified from the electronic search of which 44 studies were selected based on the inclusion and exclusion criteria. Table 1 gives an overview of all included studies. 
Table 1 Overview of included studies

\begin{tabular}{|c|c|c|c|c|c|c|}
\hline Study & $\begin{array}{l}\text { Movement } \\
\text { Visualisation }\end{array}$ & Immersion & $\begin{array}{l}\text { Robotic } \\
\text { device }\end{array}$ & $\begin{array}{l}\text { Motor func- } \\
\text { tion }\end{array}$ & $\begin{array}{l}\text { Sample popu- } \\
\text { lation }\end{array}$ & Sample size \\
\hline Aiello [35] & Indirect MV: OF & Non & No & Gait & $\begin{array}{l}\text { T:MS } \\
\text { C: }-\end{array}$ & $\begin{array}{l}\text { T: } 10 \\
\text { C: }-\end{array}$ \\
\hline Cikajlo [36] & Indirect MV: OF & Non & No & Balance & $\begin{array}{l}\text { T: Stroke } \\
\text { C: Stroke }\end{array}$ & $\begin{array}{l}\mathrm{T}: 6 \\
\mathrm{C}: 22\end{array}$ \\
\hline Fung [37] & Indirect MV: OF & Semi & No & Gait & $\begin{array}{l}\text { T: Stroke } \\
\text { C: }-\end{array}$ & $\begin{array}{l}\text { T: } 2 \\
\text { C: }-\end{array}$ \\
\hline Fung [38] & Indirect MV: OF & Semi & No & Gait, Balance & $\begin{array}{l}\text { T: Stroke } \\
\text { C: healthy }\end{array}$ & $\begin{array}{l}\text { T: } 9 \\
\text { C: } 9\end{array}$ \\
\hline Kizony [39] & Indirect MV: OF & Semi & No & Gait & $\begin{array}{l}\text { T: Stroke } \\
\text { C: healthy }\end{array}$ & $\begin{array}{l}\mathrm{T}: 12 \\
\mathrm{C}: 10\end{array}$ \\
\hline Park [40] & Indirect MV: OF & Semi & No & Gait & $\begin{array}{l}\mathrm{T}: \mathrm{PD} \\
\mathrm{C}:-\end{array}$ & $\begin{array}{l}\mathrm{T}: 3 \\
\mathrm{C}:-\end{array}$ \\
\hline Yang [41] & Indirect MV: OF & Semi/full & No & Gait & $\begin{array}{l}\text { T: Stroke } \\
\text { C: Stroke }\end{array}$ & $\begin{array}{l}\text { T: } 11 \\
\text { C: } 9\end{array}$ \\
\hline Yang [42] & Indirect MV: OF & Non & No & Balance & $\begin{array}{l}\text { T: Stroke } \\
\text { C: Stroke }\end{array}$ & $\begin{array}{l}\text { T: } 7 \\
\text { C: } 7\end{array}$ \\
\hline $\begin{array}{l}\text { Bergmann } \\
\text { [22] }\end{array}$ & Indirect MV: OF & Non/semi & $\begin{array}{l}\text { Yes (Loko- } \\
\text { mat) }\end{array}$ & Gait & $\begin{array}{l}\text { T: Stroke } \\
\text { C: }-\end{array}$ & $\begin{array}{l}\mathrm{T}: 1 \\
\mathrm{C}:-\end{array}$ \\
\hline Walker [43] & Indirect MV: AOF & Non/semi & No & Gait & $\begin{array}{l}\text { T: Stroke } \\
\text { C: }-\end{array}$ & $\begin{array}{l}\mathrm{T}: 6 \\
\mathrm{C}:-\end{array}$ \\
\hline $\begin{array}{l}\text { Lamontagne } \\
{[31]}\end{array}$ & Indirect MV: AOF & Full & No & Gait & $\begin{array}{l}\text { Crossover: } \\
\text { (T) Stroke, } \\
\text { (C) healthy }\end{array}$ & $\begin{array}{l}\text { Crossover: } \\
\text { (T) } 12 \\
\text { (C) } 12\end{array}$ \\
\hline $\begin{array}{l}\text { Lamontagne } \\
{[44]}\end{array}$ & Indirect MV: AOF & Full & No & Gait & $\begin{array}{l}\text { Crossover: } \\
\text { (T) Stroke, } \\
\text { (C) healthy }\end{array}$ & $\begin{array}{l}\text { Crossover: } \\
\text { (T) } 10 \\
\text { (C) } 11\end{array}$ \\
\hline $\begin{array}{l}\text { Slobounov } \\
{[24]}\end{array}$ & Indirect MV: AOF & Semi & No & Balance & $\begin{array}{l}\text { T: healthy } \rightarrow \mathrm{TBI} \\
\text { (within) } \\
\text { C: healthy }\end{array}$ & $\begin{array}{l}\text { T: } 10 \\
\text { C: } 45\end{array}$ \\
\hline Betker [45] & Abstract MV:2D & Non & No & Balance & $\begin{array}{l}\text { T: Ataxia, Stroke, } \\
\text { TBI } \\
\text { C: - }\end{array}$ & $\begin{array}{l}\mathrm{T}: 3 \\
\mathrm{C}:-\end{array}$ \\
\hline Geiger [46] & Abstract MV:2D & Non & No & Balance & $\begin{array}{l}\text { T: Stroke } \\
\text { C: Stroke }\end{array}$ & $\begin{array}{l}\text { T: } 7 \\
\text { C: } 6\end{array}$ \\
\hline $\begin{array}{l}\text { Gil-Gomez } \\
\text { [47] }\end{array}$ & Abstract MV: 2D & Non/semi & No & Balance & $\begin{array}{l}\text { T: Stroke, TBI, } \\
\text { BCN } \\
\text { C: Stroke, TBI, } \\
\text { BCN }\end{array}$ & $\begin{array}{l}\text { T: } 9 \\
\text { C: } 8\end{array}$ \\
\hline Jobst [48] & Abstract MV: 2D & Non & No & Balance & $\begin{array}{l}\text { T: Ataxia } \\
\text { C1: Ataxia } \\
\text { C2: healthy }\end{array}$ & $\begin{array}{l}\mathrm{T}: 36 \\
\mathrm{C} 1: 36 \\
\mathrm{C} 2: 10\end{array}$ \\
\hline Mercier [49] & Abstract MV: 2D & Non & No & Gait & $\begin{array}{l}\text { T: Stroke } \\
\text { C: }-\end{array}$ & $\begin{array}{l}\mathrm{T}: 1 \\
\mathrm{C}:-\end{array}$ \\
\hline Forrester [50] & Abstract MV: 2D & Non & $\begin{array}{l}\text { Yes (Ankle- } \\
\text { bot) }\end{array}$ & Ankle & $\begin{array}{l}\text { T: Stroke } \\
\text { C: - }\end{array}$ & $\begin{array}{l}\mathrm{T}: 8 \\
\mathrm{C}:-\end{array}$ \\
\hline Cho [17] & $\begin{array}{l}\text { Abstract MV: 3D } \\
\& \\
\text { Avartar MV: } \\
\quad \text { Rough figure }\end{array}$ & Game & No & Balance & $\begin{array}{l}\text { T: Stroke } \\
\text { C: Stroke }\end{array}$ & $\begin{array}{l}\mathrm{T}: 11 \\
\mathrm{C}: 11\end{array}$ \\
\hline Deutsch [51] & Abstract MV: 3D & Non & $\begin{array}{l}\text { Yes (Rutgers } \\
\text { Ankle Reha- } \\
\text { bilitation } \\
\text { System) }\end{array}$ & Ankle & $\begin{array}{l}\text { Exp. } 1 \& 2 \text { : } \\
\text { T: Stroke } \\
\text { C: - }\end{array}$ & $\begin{array}{l}\text { Exp.1:T: 1, C:- } \\
\text { Exp.2:T:3, C:- }\end{array}$ \\
\hline Deutsch [52] & Abstract MV: 3D & Non & $\begin{array}{l}\text { Yes (Rutgers } \\
\text { Ankle Reha- } \\
\text { bilitation } \\
\text { System) }\end{array}$ & Ankle & $\begin{array}{l}\text { T: Stroke } \\
\text { C: - }\end{array}$ & $\begin{array}{l}\text { T: } 6 \\
\text { C: }-\end{array}$ \\
\hline
\end{tabular}


Table 1 continued

\begin{tabular}{|c|c|c|c|c|c|c|}
\hline Study & $\begin{array}{l}\text { Movement } \\
\text { Visualisation }\end{array}$ & Immersion & $\begin{array}{l}\text { Robotic } \\
\text { device }\end{array}$ & $\begin{array}{l}\text { Motor func- } \\
\text { tion }\end{array}$ & $\begin{array}{l}\text { Sample popu- } \\
\text { lation }\end{array}$ & Sample size \\
\hline $\begin{array}{l}\text { Mirleman [53, } \\
54]\end{array}$ & Abstract MV: 3D & Non & $\begin{array}{l}\text { Yes (Rutgers } \\
\text { Ankle Reha- } \\
\text { bilitation } \\
\text { System) }\end{array}$ & Ankle & $\begin{array}{l}\text { T: Stroke } \\
\text { C: Stroke }\end{array}$ & $\begin{array}{l}\text { T: } 9 \\
\text { C: } 9\end{array}$ \\
\hline Cattaneo [55] & Tracking MV & Non & No & Balance & $\begin{array}{l}\text { T: MS } \\
\text { C: }-\end{array}$ & $\begin{array}{l}\text { T: } 9 \\
\text { C: }-\end{array}$ \\
\hline Deng [56] & Tracking MV & Non & No & Ankle & $\begin{array}{l}\text { T: Stroke } \\
\text { C: Stroke }\end{array}$ & $\begin{array}{l}\mathrm{T}: 8 \\
\mathrm{C}: 8\end{array}$ \\
\hline Dunning [57] & Tracking MV & Non & No & Gait, Ankle & $\begin{array}{l}\text { T: Stroke } \\
\text { C: - }\end{array}$ & $\begin{array}{l}\mathrm{T}: 1 \\
\mathrm{C}:-\end{array}$ \\
\hline Durfee [58] & Tracking MV & Non & No & Ankle & $\begin{array}{l}\text { T: Stroke } \\
\text { C: }-\end{array}$ & $\begin{array}{l}\text { T: } 20 \\
\text { C: }-\end{array}$ \\
\hline $\begin{array}{l}\text { McClanachan } \\
\text { [59] }\end{array}$ & $\begin{array}{l}\text { Avartar MV: } \\
\text { Rough figure }\end{array}$ & Game & No & Gait, Balance & $\begin{array}{l}\text { Crossover: } \\
\text { Stroke, TBI }\end{array}$ & Crossover: 21 \\
\hline Brütsch [18] & $\begin{array}{l}\text { Avatar MV: Real- } \\
\text { istic body }\end{array}$ & Non/semi & $\begin{array}{l}\text { Yes (Loko- } \\
\text { mat) }\end{array}$ & Gait & $\begin{array}{l}\text { Crossover: } \\
\text { (T) BS-CP, TBI, } \\
\text { MMC, SLE, } \\
\text { (C) healthy }\end{array}$ & $\begin{array}{l}\text { Crossover: } \\
\text { (T) } 10 \\
\text { (C) } 14\end{array}$ \\
\hline Schuler [19] & $\begin{array}{l}\text { Avatar MV: Real- } \\
\text { istic body }\end{array}$ & Non/semi & $\begin{array}{l}\text { Yes (Loko- } \\
\text { mat) }\end{array}$ & Gait & $\begin{array}{l}\text { Crossover: } \\
\text { (T) MS, CP, Hip } \\
\text { dysplasia, } \\
\text { Cerebral } \\
\text { haemorrhage, } \\
\text { Encephalopa- } \\
\text { thy, Transverse } \\
\text { myelitis, } \\
\text { (C) healthy }\end{array}$ & $\begin{array}{l}\text { Crossover: } \\
\text { (T) } 9 \\
\text { (C) } 8\end{array}$ \\
\hline Brütsch [60] & $\begin{array}{l}\text { Avatar MV: Real- } \\
\text { istic body }\end{array}$ & Non/semi & $\begin{array}{l}\text { Yes (Loko- } \\
\text { mat) }\end{array}$ & Gait & $\begin{array}{l}\text { Crossover: } \\
\text { (T) MS, CP, Hip } \\
\text { dysplasia, } \\
\text { Cerebral } \\
\text { haemorrhage, } \\
\text { Encephalopa- } \\
\text { thy, sympto- } \\
\text { matic SCl, } \\
\text { (C) healthy }\end{array}$ & $\begin{array}{l}\text { Crossover: } \\
\text { (T) } 10 \\
\text { (C) } 8\end{array}$ \\
\hline Baram [25] & AR MV & AR & No & Gait & $\begin{array}{l}\text { T1: MS } \\
\text { T2: MS }\end{array}$ & $\begin{array}{l}\text { T1: } 10 \\
\text { T2: } 11\end{array}$ \\
\hline Baram [61] & AR MV & $A R$ & No & Gait & $\begin{array}{l}\text { T: MS } \\
\text { C: healthy }\end{array}$ & $\begin{array}{l}\text { T: } 16 \\
\text { C: } 12\end{array}$ \\
\hline Kim [62] & AR MV & AR & No & Gait, Balance & $\begin{array}{l}\text { T: Stroke } \\
\text { C: Stroke }\end{array}$ & $\begin{array}{l}\text { T: } 12 \\
\text { C: } 12\end{array}$ \\
\hline Palma [63] & AR MV & Game & No & Balance & $\begin{array}{l}\text { T:TBI } \\
\text { C:TBI }\end{array}$ & $\begin{array}{l}\mathrm{T}: 7 ? \\
\mathrm{C}: 7 ?\end{array}$ \\
\hline Sveistrup [64] & AR MV & AR & No & Balance & $\begin{array}{l}\text { T1: TBI } \\
\text { T2: TBI } \\
\text { C: TBI }\end{array}$ & $?$ \\
\hline Jaffe [65] & AR MV & $A R$ & No & Gait & $\begin{array}{l}\text { T: Stroke } \\
\text { C: Stroke }\end{array}$ & $\begin{array}{l}\text { T: } 10 \\
\text { C: } 10\end{array}$ \\
\hline Thornton [66] & AR MV & AR & No & Balance & $\begin{array}{l}\mathrm{T}: \mathrm{TBI} \\
\mathrm{C}: \mathrm{TBI}\end{array}$ & $\begin{array}{l}\mathrm{T}: 15 \\
\mathrm{C}: 12\end{array}$ \\
\hline Griffin [20] & AR MV & $A R$ & No & Gait & T: PD (within) & $\mathrm{T}: 26$ \\
\hline Ferrarin [21] & $\begin{array}{l}\text { AR MV } \\
\& \\
\text { Combined MV: } \\
\text { AR + Abstract } \\
\text { (2D) }\end{array}$ & $A R$ & No & Gait & $\begin{array}{l}\text { T: PD (within) } \\
\text { C: healthy } \\
\text { (within) }\end{array}$ & $\begin{array}{l}\mathrm{T}: 3 \\
\mathrm{C}: 3\end{array}$ \\
\hline
\end{tabular}


Table 1 continued

\begin{tabular}{lllllll}
\hline Study & $\begin{array}{l}\text { Movement } \\
\text { Visualisation }\end{array}$ & Immersion & $\begin{array}{l}\text { Robotic } \\
\text { device }\end{array}$ & $\begin{array}{l}\text { Motor func- } \\
\text { tion }\end{array}$ & $\begin{array}{l}\text { Sample popu- } \\
\text { lation }\end{array}$ & Sample size \\
\hline Walker [67] & No MV & Non & No & Balance & $\begin{array}{l}\text { T: Stroke } \\
\text { C1: Stroke }\end{array}$ & $\begin{array}{l}\text { T: } 16 \\
\text { C1: } 16\end{array}$ \\
Banz [68] & No MV & Non & $\begin{array}{c}\text { Yes (Loko- } \\
\text { mat) }\end{array}$ & Gait & $\begin{array}{l}\text { Crossover: iSCl } \\
\text { C2: } 14\end{array}$ & Crossover: 12 \\
\hline
\end{tabular}

AR augmented reality, OF optical flow, AOF active optical flow, non non-immersive, semi semi-immersive, full full-immersive, game commercial game, Ankle ankle movement training, $T$ treatment group, $C$ control group, MS multiple sclerosis, (BS-) $C P$ bilateral spastic cerebral palsy, $T B I$ traumatic brain injury, $B C N$ Benign cerebral neoplasm, (i) $S C I$ (incomplete) spinal cord injury, PD Parkinson's disease, MMC meningomyelocele, SLE systemic lupus erythematodes, healthy no neurological disorder

Table 2 Movement Visualisation (MV) Groups

\begin{tabular}{|c|c|c|}
\hline MV Group & $\mathbf{N}$ & Description \\
\hline \multirow[t]{4}{*}{ Indirect MV } & 13 & $\begin{array}{l}\text { Body movements are not directly visualized in the virtual environment. } \\
\text { Changes in context information represent indirectly the user's movement }\end{array}$ \\
\hline & & Subgroups \\
\hline & & $\begin{array}{l}\text { Optical flow }(\mathrm{N}=11) \text { : Motion of patterns or objects create a naturalistic } \\
\text { illusion of movement in the virtual environment. Goal is usually navigation } \\
\text { through a virtual scenario (e.g. supermarket) }\end{array}$ \\
\hline & & $\begin{array}{l}\text { Active optical flow }(\mathrm{N}=3) \text { : Motion of patterns or objects during movement } \\
\text { in the virtual environment is manipulated with the purpose to influence } \\
\text { the user's behavior (e.g. acceleration of optical flow) }\end{array}$ \\
\hline \multirow[t]{4}{*}{ Abstract MV } & 11 & $\begin{array}{l}\text { The user's movement is represented in a (non-anthropomorphic) computer } \\
\text { graphic. Main goal relies on the correct execution of the task }\end{array}$ \\
\hline & & Subgroups \\
\hline & & 2D Exercise $(\mathrm{N}=6)$ : tasks performance in a two dimensional environment \\
\hline & & 3D Exercise $(\mathrm{N}=5)$ : task performance in a three dimensional environment \\
\hline Augmented reality (AR) MV & 9 & $\begin{array}{l}\text { Visualisation of the user's real body supplemented with virtual Performance } \\
\text { Feedback and/or virtual Context Information (e.g. Sony Eye Toy, AR-glasses). } \\
\text { This also includes Augmented Virtuality }\end{array}$ \\
\hline \multirow[t]{5}{*}{ Avatar MV } & 5 & Real movements are represented through a virtual body (or body part) \\
\hline & & Subgroups \\
\hline & & $\begin{array}{l}\text { Realistic body (or body part) }(\mathrm{N}=3) \text { : Representation visually and kinemati- } \\
\text { cally close to the real body }\end{array}$ \\
\hline & & $\begin{array}{l}\text { Rough figure }(\mathrm{N}=2) \text { : Simple body representation with some aspects of real } \\
\text { appearance and movements (e.g. Mii avatar in Nintendo Wii) }\end{array}$ \\
\hline & & $\begin{array}{l}\text { Mirrored body (or body part) }(\mathrm{N}=0) \text { : Realistic body representation with mir- } \\
\text { rored visual and movement information }\end{array}$ \\
\hline Tracking MV & 4 & $\begin{array}{l}\text { Continuous adjustment of body movement with an external visual input (e.g. } \\
\text { follow a given trajectory). Explicit goal is the correctness of the movement } \\
\text { execution }\end{array}$ \\
\hline Combined MV & 1 & $\begin{array}{l}\text { Visualisation consists of more than one MV type (e.g. indirect MV on an aug- } \\
\text { mented reality device) }\end{array}$ \\
\hline No MV & 2 & $\begin{array}{l}\text { Body movements are not represented in the virtual environment. Visualisation } \\
\text { during rehabilitation training is exclusively based on Performance Feedback }\end{array}$ \\
\hline
\end{tabular}

\section{Categorisation of movement visualisation groups}

The analyses of the visual information in the 44 included articles led to a differentiation of seven movement visualisation groups: indirect $M V$, abstract $M V$, augmented reality (AR) MV, avatar MV, tracking MV, combined MV, and no MV (shown in Table 2).

There were several studies that needed careful analysis of the MV to be correctly grouped. The study from Cho et al. [17] was grouped twice, into the MV groups Avatar 
and Abstract groups, because the authors used several different balance games. They employed the Nintendo Wii balance board with either visualisations of the participants' body movements through an avatar figure (Mii avatar of the Nintendo Wii) or abstract two- or three-dimensional games without an avatar.

Considering only the information provided in the included paper from Brütsch et al. [18] the two visualisation conditions within the described study seemed to fall within the visualisation groups Avatar MV and Indirect MV. However, the authors of this review were personally informed by the research group that in both conditions the body movements of the participants were represented as an avatars as in a related publication of the same research group [19].

Moreover, the study from Griffin et al. [20] was classified into augmented reality group alone. In this article, 26 participants with Parkinson's disease induced mobility issues walked through a corridor while receiving information via AR glasses adding visual stimuli to the real environment. The visual conditions included (a) a control condition with VR glasses showing a static image of a rectangle, (b) stripes simulating optical flow (further divided as coherent and reversed visual flow), (c) a rhythmic cueing stimulus transmitting red and black full-screen flashing, and (d) a control condition without VR glasses showing transverse lines on the floor. Neither of the optical flow condition, nor the rhythmic cueing stimulus was synchronised to walking speed or step rhythm. Therefore, the only information on the participants body movements provided was the image of the real body through the colourless lenses.

Also, the study by Ferrarin et al. [21] presented different optical flow stimuli. In this paradigm, the AR glasses drifted forward and backward. Similar to the study from Griffin at el. [20], the rhythm of this visual information was not synchronised to walking speed or step rhythm and hence it could not be classified as an MV. However, there was additional experimental condition in which a visual stimulus was applied on the side of the glasses of the leg that was right before the next step. This attentional signal was activated through data recorded from a foot-switch on the contralateral foot of the signal side, indicating the end of the swing phase of the contralateral leg. This information was classified as an abstract MV and thus the paper was grouped twice into the augmented reality group for the experimental conditions with optical flow stimuli and into combined MV with an augmented reality visualisation of the real body. The latter was presented together with abstract two-dimensional MV information of the movement execution for the foot-switch condition.

In the study by Bergmann and co-workers [22], the classification of the MV was not clear. In this case the study presented a virtual scenario during a robot-assisted walking task to a participant with a hemiparesis following stroke. The visualisation consisted of an active optic flow in form of a moving virtual forest along a red dotted walking path; that moved faster or slower synced to patient's movement effort within the robotic device. Also a walking dog was presented and the goal of the task was to keep the movement effort as high as necessary for the dot to stay under the dog. In this case the body's movement was represented both an indirect movement of the virtual scene and an abstract visualisation in form of a dot. In this review, the applied MV was categorised into the Indirect MV group because the visualisation of the dot was mainly applied as an instrument of the performance feedback within the walking task. Nevertheless, it would 
also be possible to consider the visualisation as combined MV with an indirect and an abstract MV.

One study by Sloubounov et al. [23], which was categorized into indirect MV in previously published findings $[14,15]$ had to be excluded following detailed consideration. The visualisation applied in this study showed that it was not a MV under consideration. Twelve healthy volunteers performed baseline static standing for 3 blocks of eight conditions on a force platform with an assessment of kinematic through flock of birds motion analysis system and goniometer positioned at right ankle. A black and white striped room was displayed 3D stereo virtual field and synchronized with the motion tracking system. The variation of the conditions consisted of anterior-posterior oscillations of the whole room, the front wall or the side wall at 0.3 or $0.6 \mathrm{~Hz}$. Also, a whole room lateral roll at 0.3 and $0.6 \mathrm{~Hz}$ was performed. In a second experiment, the participants were exposed to the same virtual room motion conditions via mirror mounted on a head coil in supine position in an fMRI scanner. Since the participant had the instruction to stand "as steady as possible" ([23], p. 189) and the induced change in kinematics through a simulation of room movement was not linked to a change of visualisation, the visual information in this experiments is better to be classified as a manipulation in Context Information rather than an application of Indirect MV of (active) optical flow. Moreover, no performance feedback was given so that there was no information on body movement given at all.

\section{Movement visualisation comparison}

Most of the included studies did not have their main goal on exploring the effect of MV on motor learning. Instead they addressed to investigate the effect of a VR motor intervention in general. Only a few studies allowed to extract information about the influence of different MV on motor learning, even though it was not the focus of the referring studies. Therefore subsequently we summarise the extracted relevant information. In two studies two MV-groups Avatar and Abstract [17] and augmented reality and combined MV [21] were applied within the same game intervention. Three studies investigate different visualisations within a same MV group [20, 24, 25].

In a second included paper by Sloubonov et al. [24], a comparison of different MVs was performed within one study. In this study, 55 University athletes at risk for traumatic brain injury underwent two experiments with balance force plates and a motion analysis system in front of a 3D wall screen projection. Three follow up testing were conducted with 10 participants which suffered traumatic brain injury (mild concussion) after the baseline recording. The first experiment was comparable with the previous mentioned study by the research group [23]. The participants had to stand as still as possible while applying virtual scenes of moving black and white stripes simulating visual field motion in three different conditions. During the second experiment subjects produced whole body postural movements in forward-backward and lateral directions while viewing visual field randomised across 3 sub-conditions: (1) dark, (2) moving room matched at subject's body motion at $180^{\circ}$ in-phase, and (3) moving room matched at subject's body motion at $180^{\circ}$ out-of-phase. Importantly the variations in active manipulation of the virtual scene (condition 2 and 3 ) represent a direct comparison of the subgroups "optical flow" (optical flow in accordance to natural movements) and "active optical flow" 
(manipulated optical flow, in this case conflicting with natural movements) of Indirect MVs within our classification. The analysis of centre of pressure measure and coherence measure based on cross-spectra estimate of the weight shifts showed for the second experiment in all subjects prior to concussion, a preserved balance i.e. coherent oscillatory postural movements that matched virtual room motion, for both sub-condition 2 and 3. Post-injury a decrease in coherence was present at day 10 and day 30. The participants presenting a mild concussion were not able to stay in balance while presenting a conflicting active optical flow. In contrast, subjects post-injury showed a decrease in coherence on day 3 which improved by day 10 and returned to baseline by day 30 during the task with no external manipulation of the virtual scene (experiment 1 ).

As mentioned previously Ferrarin and colleagues [21] applied augmented reality and combined MV of augmented reality and abstract visualisation in different experimental conditions within the same study. However, a direct comparison of the MV is not possible because the context information varied highly between the conditions. Only during the augmented reality MV an augmented visual field motion was presented whereas in the combined MV task the context information consisted of exclusively the real environment.

Two additional studies [20,25] compared the applied visual information within the augmented reality group in subjects with Parkinson's disease and multiple sclerosis. In both studies it was possible for the participants to view their body moving in real-time through the real environment augmented with geometrical patterns. But the visual feedback of the movement per se was not changed. Therefore, the results of these studies could not be considered to provide any guideline for the application of MV, since this information was kept constant across the settings.

\section{Discussion}

In this systematic literature review 43 publications on application of VR-based therapy for lower extremity motor rehabilitation in neurological population, were analysed for their movement visualisation. Seven distinct groups implementing user's movement into the virtual environment were differentiated as: indirect MV, abstract MV, augmented reality $M V$, avatar MV, tracking MV, combined MV, and no MV. Unfortunately, no included study directly compared MV groups. Therefore, no conclusion on potential difference on motor learning based on MV groups can be driven.

The visualisation of optical flow or active optical flow (indirect MV) was the most frequently applied and investigated MV for rehabilitation of gait and balance. Only within this MV group diverse forms of visualisations could be analysed and compared.

In addition to visual cues and complex scenes, movement of the body in space continuously generates an optic flow field [26]. The optic signals provide information on direction of locomotion [27] and can modulate speed, in addition to adapting locomotion to the uneven terrain and avoid obstacles [28, 29]. Furthermore, alteration in optic flow speed in a virtual environment is shown to modulate gait speed in healthy subjects [30], with faster optic flow resulting in decrease of walking speed in stroke individuals [31]. Thus, this visual stimulation, via complex scenes or optic flow, can affect locomotion.

In a previously published analysis on VR-based neurological movement rehabilitation for the upper extremity, the most applied MV group was the use of an Avatar, in 
which the person's arm and hand movements were proportionally represented in the virtual environment $[13,14]$. This may not be a coincidence. Differences in MV selection between upper and lower extremities applications suggest that further research needs to be conducted on direct visualisation for the upper extremity and indirect visualisation for the lower extremities. Although there is no evidence that direct and indirect display of a user's movement has an influence on motor outcome it is possible that there is a difference in effectiveness between MV of upper and lower extremities. This could be related to the visual information received in normal motor execution. Upper extremities are used independently for a single or bilateral activity. In contrast, lower limbs are most commonly used for locomotion. Studies have shown that locomotion seems to rely more on "central pattern generators", integrating rhythmic sensorimotor information with information on body localisation rather than visual information about the position of the lower limbs in space [32]. In contrast, the majority of humans' tasks with arms and hands require visual information on the body related to the environment, e.g. for grasping an object correctly [33]. Therefore, it may be more effective to train lower extremities with indirect MV showing the movement of the environment according to the displacement of the body during walking without a direct presentation of the limbs. In contrast, motor learning of hand and arm movements may need more information on how exactly the movement of the extremity looks like in relation to the environment.

As mentioned above there is currently insufficient evidence for any concrete conclusion. The tendency, however, gives a reason to expand research on similarities and differences in MV on motor learning of upper and lower extremities. The analysis of included papers on MV comparison showed that only one included paper reported an appropriate study design for this purpose. The study from Sloubonov et al. [24] showed a persistent disturbance in balance for participants with traumatic brain injuries until 30 days after injury only in the active (conflicting) optical flow condition and not for the natural optical flow condition. Moreover, these findings were not observed for the healthy individuals. Based on this, the authors concluded that VR applications can be used to examine the effect on balance and "potentially be considered within the scope of existing grading scales of concussion" ([24], p. 191). Nevertheless, it has to be summarised that there is insufficient evidence to conclude about different effects of the several MV groups on walking or balance.

The current systematic review is limited in some aspects. First, only VR applications aimed at rehabilitation of neurologically impaired population were included. It is possible, however, that VR-based systems promote motor learning in healthy individuals or people with orthopaedic restrictions, requiring other MVs. To our understanding and knowledge, it is currently unclear if there is a difference of MV on motor learning among these populations. Another limitation is that rehabilitation of neuro-cognitive dysfunctions may have importance for an optimal MV design. Moreover, there may be an interaction of movement visualisation with performance feedback and context information on motor learning. For example, the same movement visualisation probably has another effect when combined with knowledge of results (KR) than with knowledge of performance (KP), both performance feedback components, and vice versa. This study does also not conclude on possible effects or interactions of information from other modalities like sound or haptic feedback, which was provided in the included studies. 
Future studies should explore the relationship of VR information components in several modalities on human behaviour and motor outcome. Finally, there were several included studies that applied robotic technologies. A previous study compared the effects of VR application alone in contrast to a passive exoskeleton and an end effector haptic device on upper extremity training in post-stroke participants [34]. All conditions showed increased clinical outcome measurements after the trial with no significant difference between different technical applications. However, only in the haptic feedback condition the achieved gains in ability were retained to the follow up assessment 12 weeks postintervention [34]. In this study the virtual environment was kept constant for all three applications. The results suggest that there may be different motor learning strategies involved when a patient is assisted in movement execution. Therefore, potential interaction of MV with robotic devices should be considered in future research.

Today a vast number of VR-based rehabilitation applications are available. Most of them are effective, efficient and provide an additional tool to conventional therapy [2]. However, there is lack of knowledge on the mechanism of effect with use of these interventions. This makes the creation of new interventions possibly inefficient with increase in cost for the evaluation. Information on how virtual rehabilitation features influence motor learning is necessary and should provide important insight in how these features need to be modified according to the therapeutic goal.

The results of this review are a first step on systemizing VR-based motor rehabilitation applications. The MV groups showed how diverse VR training can be implemented and the limited knowledge about the effect of these distinct visualisations. Based on the presented MV groups in this review, future research could be carried out focusing on and investigating the effect of diverse visualisation on motor outcome and other rehabilitation related aspects such as motivation and presence [6].

\section{Conclusions}

This study was performed in order to categorize and analyse movement visualisation of current available literature on lower extremity VR-based motor neuro-rehabilitation. In the systematic literature search it was possible to describe seven distinct groups of MV indicating that movements are currently displayed very differently in virtual rehabilitation environments. Unfortunately, little is known about the effect of different MVs on motor outcome. There is not enough information on how different MV influences motor learning within the included studies so that no recommendation on MV for specific purpose of interventions can be deduced at this stage. Additional research in is necessary to optimize future interventions.

\section{Abbreviations}

VR: virtual reality; MV: movement visualisation; AR: augmented reality.

\section{Authors' contributions}

LFS carried out the data acquisition, analysed and interpreted the data, and drafted the manuscript. OC interpreted the data and assisted to draft the manuscript. KM analysed and interpreted the data and drafted the manuscript. HS participated in the design of the study, helped to draft the manuscript, and gave critical revision. JK conceived of the study, and participated in its design and coordination. CD conceived of the study, participated in its design and coordination and gave critical revision of the manuscript. All authors read and approved the final manuscript.

\section{Author details}

${ }^{1}$ Rehabilitation Robotics Group (TU Berlin/ Fraunhofer IPK), Department of Industrial Automation Technology, Technische Universität Berlin, Pascalstr. 8-9, 10587 Berlin, Germany. ${ }^{2}$ DFG Research Training Group Prometei, Technische 
Universität Berlin, Marchstr. 23, 10587 Berlin, Germany. ${ }^{3}$ Institute Humans in Complex Systems, School of Applied Psychology, University of Applied Sciences and Arts Nortwestern Switzerland, Riggenbachstrasse 16, Olten, Switzerland. ${ }^{4}$ School of Physical and Occupational Therapy, McGill University, 3654 Promenade Sir William Osler Montreal, Quebec H3G 1Y5, Canada. ${ }^{5}$ Rehabilitation Robotics Group (Fraunhofer IPK TU Berlin), Department of Automation Technology, Fraunhofer Institute for Production Systems and Design Technology (IPK), Pascalstr. 8-9, 10587 Berlin, Germany. ${ }^{6}$ Department of Neurological Rehabilitation, MEDIAN Klinik Berlin-Kladow, Kladower Damm 223, 14089 Berlin, Germany. ${ }^{7}$ Center for Stroke Research Berlin, Charité-University Medicine Berlin, Charitéplatz 1, 10117 Berlin, Germany.

\section{Acknowledgements}

The authors would like to thank Mareike Okrafka and Claire Lydia Fritzsch for their assistance in conducting and preparing literature searches.

\section{Competing interests}

The authors declare that they have no competing interests.

\section{Declarations}

This article has been published as part of BioMedical Engieering OnLine Vol 15 Suppl 3, 2016: Towards Active Lower Limb Prosthetic Systems: Design Issues and Solutions. The full contents of the supplement are available online at http:// biomedical-engineering-online.biomedcentral.com/articles/supplements/volume-15-supplement-3.

\section{Funding}

The Research Training Group "Prometei" is funded by the German Research Foundation (DFG). Preliminary work was supported by funding of the Center of Stroke Research Berlin (Flex Funds, CS-2009-10) and the MEDIAN Klinik Berlin-Kladow. The publication costs were covered by the authors.

\section{Published: 19 December 2016}

\section{References}

1. Christ O, Reiner M. Perspectives and possible applications of the rubber hand and virtual hand illusion in noninvasive rehabilitation: technological improvements and their consequences. Neurosci Biobehav Rev. 2014;8:33-44.

2. Laver KE, George S, Thomas S, Deutsch JE, Crotty M. Virtual reality for stroke rehabilitation. Cochrane Database Syst Rev. 2011;9:CD008349.

3. International Society for Virtual Rehabilitation (ISVR). http://isvr.org/about-us/by-laws. Accessed 26 Oct 2016.

4. Holden MK. Virtual environments for motor rehabilitation: review. Cyberpsychol Behav. 2005;8:187-211.

5. Valvoda JT. Virtual humanoids and presence in virtual environments. Ph.D. thesis. Rheinisch-Westfälische Technische Hochschule Aachen; Fakultät für Mathematik, Informatik und Naturwissenschaften; 2007.

6. Schüler T, Ferreira dos Santos L, Hoermann S. Harnessing the experience of presence for virtual motor rehabilitation: towards a guideline for the development of virtual reality environments. In: Proceedings of the 10th international conference on disability, virtual reality and associated technologies (ICDVRAT): 2-4 September 2014; Gothenburg. Sharkey PM, Pareto L, Broeren J, Rydmark M, editors. Reading: The University of Reading; 2014. p. 373-6.

7. Calayan LSM, Dizon JMR. A systematic review on the effectiveness of mental practice with motor imagery in the neurologic rehabilitation of stroke patients. Internet J Allied Health Sci Pract. 2009;7:10.

8. Thieme H, Mehrholz J, Pohl M, Behrens J, Dohle C. Mirror therapy for improving motor function after stroke. Cochrane Database Syst Rev. 2012;3:CD008449.

9. Zimmermann-Schlatter A, Schuster C, Puhan MA, Siekierka E, Steurer J. Efficacy of motor imagery in post-stroke rehabilitation: a systematic review. J Neuroeng Rehabil. 2008;5:8.

10. da Silva Cameirão M, Bermúdez i Badia S, Duarte E, Verschure PF. Virtual reality based rehabilitation speeds up functional recovery of the upper extremities after stroke. Restor Neurol Neurosci. 2011;29:287-98.

11. Schüler T, Drehlmann S, Kane F, von Piekartz H. Abstract virtual environment for motor rehabilitation of stroke patients with upper limb dysfunction. A pilot study. In: Proceedings of the international conference on virtual rehabilitation (ICVR) 2013: 26-29 August 2013. Philadelphia: IEEE Xplore; 2013. p. 184-5.

12. Hoermann S, Franz EA, Regenbrecht H. Referred sensations elicited by video-mediated mirroring of hands. PLoS ONE. 2012;7:e50942.

13. Ferreira dos Santos L, Schmidt H, Kruger J, Dohle C. Visualization of virtual reality neurological motor rehabilitation of the upper limb-a systematic review. In: Proceedings of the international conference on virtual rehabilitation (ICVR) 2013: 26-29 August 2013. Philadelphia: IEEE Xplore; 2013. p. 176-7.

14. Ferreira dos Santos L, Schmidt H, Dohle C, Krüger J. Avatare in der virtuellen Neurorehabilitation der unteren und oberen Extremitäten. In: Proceedings of the 10th Berliner Werkstatt Mensch-Maschine-Systeme: 10-12 October 2013; Berlin. Brandenburg E, Doria L, Gross A, Günzler T, Smieszek H, editors. Berlin: Universitätsverlag der TU Berlin; 2013. p. 282-7.

15. Ferreira dos Santos L, Schmidt H, Krüger J, Dohle C. Visuelles Feedback in der virtuellen Neurorehabilitation der oberen und unteren Extremitäten - ein systematisches Review. In: Proceedings of the 23rd Jahrestagung der Deutschen Gesellschaft für Neurorehabilitation: 12-14 December 2013; Berlin. Neurologie \& Rehabilitation. 2013;19:381-2.

16. Kalawsky RS. Exploiting virtual reality techniques in education and training: technological issues. 1996. http://www. agocg.ac.uk/reports/virtual/vrtech/title.htm. Accessed 26 Oct 2016.

17. Cho KH, Lee KJ, Song CH. Virtual-reality balance training with a video-game system improves dynamic balance in chronic stroke patients. Tohoku J Exp Med. 2012;228:69-74. 
18. Brütsch K, Koenig A, Zimmerli L, Merillat-Koeneke S, Riener R, Jäncke L, van Hedel HJ, Meyer-Heim A. Virtual reality for enhancement of robot-assisted gait training in children with central gait disorders. J Rehabil Med. 2011;43:493-9.

19. Schuler T, Brütsch K, Müller R, van Hedel HJ, Meyer-Heim A. Virtual realities as motivational tools for robotic assisted gait training in children: a surface electromyography study. Neuro Rehabil. 2011;28:401-11.

20. Griffin HJ, Greenlaw R, Limousin P, Bhatia K, Quinn NP, Jahanshahi M. The effect of real and virtual visual cues on walking in Parkinson's disease. J Neurol. 2011;258:991-1000

21. Ferrarin M, Brambilla M, Garavello L, Di Candia A, Pedotti A, Rabuffetti M. Microprocessor-controlled optical stimulating device to improve the gait of patients with Parkinson's disease. Med Biol Eng Comput. 2004;42:328-32.

22. Bergmann J, Krewer C, Müller F, Koenig A, Riener R. Virtual reality to control active participation in a subacute stroke patient during robot-assisted gait training. In: Proceedings of the IEEE international conference on rehabilitation robotics: 29th June to 1st July 2011; Zürich. 5975407.

23. Slobounov S, Wu T, Hallett M, Shibasaki H, Slobounov E, Newell K. Neural underpinning of postural responses to visual field motion. Biol Psychol. 2006;72:188-97.

24. Slobounov S, Slobounov E, Newell K. Application of virtual reality graphics in assessment of concussion. Cyberpsychol Behav. 2006;9:188-91.

25. Baram Y, Miller A. Glide-symmetric locomotion reinforcement in patients with multiple sclerosis by visual feedback. Disabil Rehabil Assist Technol. 2010;5:323-6.

26. Gibson JJ. Visually controlled locomotion and visual orientation in animals. Br J Psychol. 1958:49:182-94.

27. Warren WH, Kay BA, Zosh WD, Duchon AP, Sahuc S. Optic flow is used to control human walking. Nat Neurosci. 2001:4:467-78

28. Chapman GJ, Hollands MA. Age-related differences in visual sampling requirements during adaptive locomotion. Exp Brain Res. 2010;201:467-78.

29. Hollands MA, Marple-Horvat DE. Coordination of eye and leg movements during visually guided stepping. J Mot Behav. 2001;33:205-16.

30. Prokop T, Schubert M, Berger W. Visual influence on human locomotion. Modulation to changes in optic flow. Exp Brain Res. 1997;114:63-70.

31. Lamontagne A, Fung J, McFadyen BJ, Faubert J. Modulation of walking speed by changing optic flow in persons with stroke. J Neuroeng Rehabil. 2007:4:22.

32. Lacquaniti F, Ivanenko YP, Zago M. Development of human locomotion. Curr Opin Neurobiol. 2012;22:822-8.

33. Jeannerod M. The neural and behavioural organization of goal-directed movements. New York: Clarendon Press/ Oxford University Press (Oxford psychology series, No. 15); 1988.

34. Cameirão MS, Bermúdez i Badia S, Duarte E, Frisoli A, Verschue PFMJ. The combined impact of virtual reality neurorehabilitation and its interfaces on upper extremity functional recovery in patients with chronic stroke. Stroke. 2012;43:2720-8.

35. Aiello E, Peruzzi A, Fadda P, Serra A, Sidore D, Solinas D, Sotgiu S, Varone C, Della Croce U, Mirelman A. New virtual reality protocol for gait training in patients with multiple sclerosis. Gait Posture. 2012;35(Suppl 1):46-7.

36. Cikajlo I, Rudolf M, Goljar N, Burger H, Matjacic Z. Telerehabilitation using virtual reality task can improve balance in patients with stroke. Disabil Rehabil. 2012;34:13-8.

37. Fung J, Richards CL, Malouin F, McFadyen BJ, Lamontagne A. A treadmill and motion coupled virtual reality system for gait training post-stroke. Cyberpsychol Behav. 2006;9:157-62.

38. Fung J, Perez CF. Sensorimotor enhancement with a mixed reality system for balance and mobility rehabilitation. In: Proceedings of the 33rd annual international conference of the IEEE engineering in medicine and biology society: 30th August to 3rd September 2011; Boston. p. 6753-7.

39. Kizony R, Levin MF, Hughey L, Perez C, Fung J. Cognitive load and dual-task performance during locomotion poststroke: a feasibility study using a functional virtual environment. Phys Ther. 2010;90:252-60.

40. Park H-S, Yoon JW, Kim J, Iseki K, Hallett M. Development of a vr-based treadmill control interface for gait assessment of patients with Parkinson's disease. In: Proceedings of the IEEE international conference on rehabilitation robotics: 29th June to 1st July 2011; Zürich. p. 5975463.

41. Yang Y-R, Tsai M-P, Chuang T-Y, Sung W-H, Wang R-Y. Virtual reality-based training improves community ambulation in individuals with stroke: a randomized controlled trial. Gait Posture. 2008;28:201-6.

42. Yang S, Hwang W-H, Tsai Y-C, Liu F-K, Hsieh L-F, Chern J-S. Improving balance skills in patients who had stroke through virtual reality treadmill training. Am J Phys Med Rehabil. 2011;90:969-78.

43. Walker ML, Ringleb SI, Maihafer GC, Walker R, Crouch JR, van Lunen B, Morrison S. Virtual reality-enhanced partia body weight-supported treadmill training poststroke: feasibility and effectiveness in 6 subjects. Arch Phys Med Rehabil. 2010:91:115-22.

44. Lamontagne A, Fung J, McFadyen B, Faubert J, Paquette C. Stroke affects locomotor steering responses to changing optic flow directions. Neurorehabil Neural Repair. 2010:24:457-68

45. Betker AL, Szturm T, Moussavi ZK, Nett C. Video game-based exercises for balance rehabilitation: a single-subject design. Arch Phys Med Rehabil. 2006;87:1141-9.

46. Geiger RA, Allen JB, O'Keefe J, Hicks RR. Balance and mobility following stroke: effects of physical therapy interventions with and without biofeedback/forceplate training. Phys Ther. 2001;81:995-1005.

47. Gil-Gomez J-A, Llorens R, Alcaniz M, Colomer C. Effectiveness of a wii balance board-based system (ebavir) for balance rehabilitation: a pilot randomized clinical trial in patients with acquired brain injury. J Neuroeng Rehabil. 2011;8:30.

48. Jobst U. Posturographie-biofeedback-training bei Gleichgewichtsstörungen. Fortschr Neurol Psyc. 1989;57:74-80.

49. Mercier C, Bourbonnais D, Bilodeau S, Lemay JF, Cross P. Description of a new motor re-education programme for the paretic lower limb aimed at improving the mobility of stroke patients. Clin Rehabil. 1999;13:199-206.

50. Forrester LW, Roy A, Krebs HI, Macko RF. Ankle training with a robotic device improves hemiparetic gait after a stroke. Neurorehabil Neural Repair. 2011;25:369-77.

51. Deutsch JE, Merians AS, Adamovich S, Poizner H, Burdea GC. Development and application of virtual reality technology to improve hand use and gait of individuals post-stroke. Restor Neurol Neurosci. 2004;22:371-86. 
52. Deutsch JE, Lewis JA, Burdea G. Technical and patient performance using a virtual reality-integrated telerehabilitation system: preliminary finding. IEEE Trans Neural Syst Rehabil Eng. 2007;15:30-5.

53. Mirelman A, Bonato $P$, Deutsch JE. Effects of training with a robot-virtual reality system compared with a robot alone on the gait of individuals after stroke. Stroke. 2009;40:169-74.

54. Mirelman A, Patritti BL, Bonato P, Deutsch JE. Effects of virtual reality training on gait biomechanics of individuals post-stroke. Gait Posture. 2010;31:433-7.

55. Cattaneo D, Cardini R. Computerized system to improve voluntary control of balance in neurological patients. Cyberpsychol Behav. 2001;4:687-94.

56. Deng H, Durfee WK, Nuckley DJ, Rheude BS, Severson AE, Skluzacek KM, Spindler KK, Davey CS, Carey JR. Complex versus simple ankle movement training in stroke using telerehabilitation: a randomized controlled trial. Phys Ther. 2012;92:197-209.

57. Dunning K, Levine P, Schmitt L, Israel S, Fulk G. An ankle to computer virtual reality system for improving gait and function in a person 9 months poststroke. Top Stroke Rehabil. 2008;15:602-10.

58. Durfee W, Carey J, Nuckley D, Deng J. Design and implementation of a home stroke telerehabilitation system. In: Proceedings of the annual international conference of the IEEE engineering in medicine and biology society: 2-6 September 2009; Minneapolis. p. 2422-5.

59. McClanachan NJ, Kuys SS, Gesch J, Fleming J. Feasibility of the Nintendo Wii-Fit and its effect on endurance, gait and balance in people with an acquired brain injury [abstract]. Neurorehabil Neural Repair. 2012;26:83.

60. Brütsch K, Schuler T, Koenig A, Zimmerli L, Koeneke SM, Lünenburger L, Riener R, Jäncke L, Meyer-Heim A. Influence of virtual reality soccer game on walking performance in robotic assisted gait training for children. J Neuroeng Rehabil. 2010;7:15

61. Baram Y, Miller A. Virtual reality cues for improvement of gait in patients with multiple sclerosis. Neurology. 2006;66:178-81.

62. Kim JH, Jang SH, Kim CS, Jung JH, You JH. Use of virtual reality to enhance balance and ambulation in chronic stroke: a double-blind, randomized controlled study. Am J Phys Med Rehabil. 2009;88:693-701.

63. Palma P, McFarling E, Flynn S, Romero T, Van Den Eynde E, Sholas M. Is virtual reality gaming an effective adjunct to traditional therapy in children and adolescents with traumatic brain injury? In: Proceedings of the APTA combined section meetings-neurology section: 8-12 February 2012; Chicago. [abstract].

64. Sveistrup H, McComas J, Thornton M, Marshall S, Finestone H, McCormick A, Babulic K, Mayhew A. Experimental studies of virtual reality-delivered compared to conventional exercise programs for rehabilitation. Cyberpsychol Behav. 2003;6:245-9.

65. Jaffe DL, Brown DA, Pierson-Carey CD, Buckley EL, Lew HL. Stepping over obstacles to improve walking in individuals with poststroke hemiplegia. J Rehabil Res Dev. 2004;41:283-92.

66. Thornton M, Marshall S, McComas J, Finestone H, McCormick A, Sveistrup H. Benefits of activity and virtual reality based balance exercise programmes for adults with traumatic brain injury: perceptions of participants and their caregivers. Brain Inj. 2005;19:989-1000.

67. Walker C, Brouwer BJ, Culham EG. Use of visual feedback in retraining balance following acute stroke. Phys Ther. 2000;80:886-95.

68. Banz R, Bolliger M, Colombo G, Dietz V, Lunenburger L. Computerized visual feedback: an adjunct to robotic-assisted gait training. Phys Ther. 2008;88:1135-45.

Submit your next manuscript to BioMed Central and we will help you at every step:

- We accept pre-submission inquiries

- Our selector tool helps you to find the most relevant journal

- We provide round the clock customer support

- Convenient online submission

- Thorough peer review

- Inclusion in PubMed and all major indexing services

- Maximum visibility for your research

Submit your manuscript at www.biomedcentral.com/submit 